\title{
Controle genético do comprimento do pedúnculo em feijão-caupi
}

Maurisrael de Moura Rocha ${ }^{(1)}$, Kênnya Jhouanny Martins de Carvalho(2), Francisco Rodrigues Freire Filho(1), Ângela Celis de Almeida Lopes ${ }^{(2)}$, Regina Lúcia Ferreira Gomes ${ }^{(2)}$ e Iradenia da Silva Sousa ${ }^{(2)}$

(1)Embrapa Meio-Norte, Caixa Postal 01, CEP 64006-220 Teresina, PI. E-mail: mmrocha@cpamn.embrapa.br, freire@cpamn.embrapa.br (2)Universidade Federal do Piauí, Departamento de Biologia, Campus Ministro Petrônio Portela, Bairro Ininga, CEP 64049-550 Teresina, PI. E-mail: kennya@bol.com.br, acalopes@ufpi.br, rlfgomes@ufpi.br, iradeniabio@yahoo.com.br

Resumo - O objetivo deste trabalho foi estudar o controle genético do caráter comprimento do pedúnculo em feijão-caupi (Vigna unguiculata). Para isso, foi realizado um cruzamento entre os parentais TVx-5058-09C, de pedúnculo curto, e TE96-282-22G, de pedúnculo longo. Os parentais e as gerações $F_{1}, F_{2}, R_{1}\left(P_{1} x F_{1}\right)$ e $\mathrm{RC}_{2}\left(\mathrm{P}_{2} \mathrm{XF}_{1}\right)$ foram avaliados em delineamento de blocos ao acaso, com quatro repetições. Foram estimados: variâncias fenotípica, genotípica, ambiental, aditiva e de dominância; herdabilidades no sentido amplo e restrito; grau médio de dominância e número mínimo de genes que determinam o caráter. O modelo aditivodominante foi adequado para explicar a variação observada. $\mathrm{O}$ efeito gênico aditivo foi o mais importante no controle do comprimento do pedúnculo, que é, aparentemente, controlado por cinco genes.

Termos para indexação: Vigna unguiculata, arquitetura de planta, colheita mecânica, herança genética, parâmetros genéticos.

\section{Genetic control of peduncle length in cowpea}

\begin{abstract}
The objective of this work was to investigate the genetic control of peduncle length in cowpea (Vigna unguiculata L.). A short peduncle cowpea line (TVx-5058-09C) was crossed with a long peduncle line (TR 96282-22G). The parents and the $\mathrm{F}_{1}, \mathrm{~F}_{2}, \mathrm{RC}_{1}\left(\mathrm{P}_{1} \mathrm{xF}_{1}\right)$, and $\mathrm{RC}_{2}\left(\mathrm{P}_{2} \mathrm{xF} \mathrm{F}_{1}\right)$ generations were evaluated in randomized block design with four replications. Genotypic, phenotypic, environmental, additive, and dominance variances for peduncle length were determined. Narrow and broad sense heritability, the degree of dominance, and the minimum number of genes determining peduncle length were estimated. The additive-dominant model was adequate to explain the observed variation. The additive gene effect was the most important in controlling peduncle length, which appeared to be controlled by five genes.
\end{abstract}

Index terms: Vigna unguiculata, plant architecture, mechanial harvesting, genetic inheritance, genetic parameters.

\section{Introdução}

O feijão-caupi, feijão-de-corda ou feijão-fradinho (Vigna unguiculata (L.) Walp.) é uma leguminosa bastante cultivada nos trópicos semiáridos da África, Brasil e Estados Unidos. No Brasil, a cultura tem grande importância nas regiões Norte e Nordeste, que têm tradição em seu cultivo, comércio e consumo. Apresenta crescente avanço na região Centro-Oeste, onde o cultivo tem sido conduzido de forma mecanizada, e é crescente a demanda por cultivares de porte ereto.

Os caracteres que formam a arquitetura da planta em feijão-caupi, tais como: hábito de crescimento e comprimento do hipocótilo, dos entrenós, dos ramos principais e secundários e do pedúnculo, podem resultar em maior ou menor acamamento das plantas, bem como permitir a colheita mecânica ou facilitar a colheita manual.
O melhoramento genético do feijão-caupi para produtividade, qualidade de grãos e arquitetura de planta permite o desenvolvimento de genótipos com características produtivas com importância comercial e com estrutura de planta adaptada à colheita mecânica. Isto torna possível a mudança no perfil do sistema produtivo e o estímulo à iniciativa empresarial para a produção em grande escala (Frota et al., 2000). Cultivares de porte semiereto, com inserção de vagens acima da folhagem e maturidade de vagens mais uniforme, têm sido desenvolvidas (Freire Filho et al., 2005, 2008).

A avaliação da natureza e magnitude dos efeitos gênicos que controlam um determinado caráter é de reconhecida importância no processo de seleção e predição do comportamento de gerações híbridas e segregantes (Cruz et al., 2004). A análise de gerações baseia-se nas relações genéticas entre médias de famílias 
relativas aos progenitores $F_{1}, F_{2}$ e retrocruzamentos 1 $\left(\mathrm{P}_{1} \mathrm{xF}_{1}\right)$ e $2\left(\mathrm{P}_{2} \mathrm{xF}_{1}\right)$, e permite avaliar a adequabilidade do modelo aditivo-dominante a um determinado caráter (Cruz, 2001).

Singh \& Ishiyaku (2000) observaram que a herança da textura do grão em feijão-caupi é controlada por dois genes complementares. Esses autores também mostraram que a pigmentação roxa em algumas partes vegetativas da planta é condicionada por dois genes e envolve efeito de dominância e epistasia. Lopes et al. (2003) concluíram que a herança do tamanho da semente é controlada por efeitos gênicos aditivos, com envolvimento de cinco genes.

O comprimento do pedúnculo representa um dos caracteres que influenciam diretamente a arquitetura da planta de feijão-caupi. Tem-se observado que genótipos de porte prostrado apresentam pedúnculos mais compridos em comparação aos genótipos de porte ereto e semiereto. Para o ideótipo de arquitetura moderna da planta de feijão-caupi, o melhoramento busca selecionar genótipos com pedúnculos mais curtos.

Avaliações do comprimento do pedúnculo em genótipos de feijão-caupi mostraram que existe grande variabilidade para o caráter, que varia de 19 a $50 \mathrm{~cm}$ (Lopes et al., 2001; Singh et al., 2003; Lal et al., 2007). Estudos de correlação entre caracteres mostraram que o comprimento do pedúnculo apresenta correlação positiva com o número de grãos por vagem, e negativa com o número de vagens por planta e peso de 100 grãos (Lopes et al., 2001). Também a produtividade de grãos é afetada pelo número de pedúnculos, número de ramificações por planta e número de vagens por pedúnculo (Ariyo, 1995).

Estudos sobre os grupos de ligação (GL) e a herança de caracteres associados com a arquitetura da planta em feijão-caupi têm sido conduzidos. Githiri et al. (1996) descobriram que o GL III contém locos gênicos relacionados ao controle do tipo de pedúnculo (simples ou ramificado), porte da planta (ereto e semiereto) e hábito de crescimento (determinado e indeterminado). Kehinde et al. (1997) identificaram genes ou blocos gênicos responsáveis pelo controle do pedúnculo cacheado no GL II. Matos Filho (2004), ao estudar a herança do comprimento e número de nós no ramo principal, concluiu que a variância de dominância foi superior à aditiva em ambos os caracteres. Machado et al. (2007) estudaram a herança da inflorescência composta na cultivar de feijão-caupi Cacheado e concluíram que ela era monogênica recessiva.

Apesar de estudos preliminares indicarem os grupos de ligação e o tipo de ação gênica envolvidos no controle do tipo e do comprimento do pedúnculo, estudos sobre a herança, o tipo de ação gênica e número de genes que controlam o caráter são escassos. O conhecimento da genética desse caráter é imprescindível na escolha de estratégias mais adequadas de seleção para melhoria da arquitetura da planta de feijão-caupi. Pal et al. (2003), ao estudar a depressão por endogamia em populações resultantes do cruzamento entre $V$. unguiculata e $V$. sesquipedalis, afirmaram que o comprimento do pedúnculo está sob ação gênica não aditiva.

Este trabalho teve como objetivo estudar o controle genético do caráter comprimento do pedúnculo, para servir de base a programas de melhoramento genético que visem à melhoria da arquitetura de planta em feijão-caupi.

\section{Material e Métodos}

Foram utilizados os genótipos de feijãocaupi TVx-5058-09C $\left(\mathrm{P}_{1}\right)$, de pedúnculo curto, e TE96-282-22G $\left(\mathrm{P}_{2}\right)$, de pedúnculo longo, com comprimentos de pedúnculos que variavam de 11,3 a 55,3 cm. Os genótipos foram oriundos do Banco Ativo de Germoplasma de feijão-caupi da Embrapa Meio-Norte.

Os cruzamentos foram realizados em condições de telado, no ano de 2003, na Embrapa Meio-Norte, Teresina, PI, a $5^{\circ} 5^{\prime} \mathrm{S}$, e $42^{\circ} 49^{\prime} \mathrm{W}$, e $72 \mathrm{~m}$ de altitude. Esta etapa foi dividida em duas fases: na primeira, obteve-se a geração $\mathrm{F}_{1}\left(\mathrm{P}_{1} \times \mathrm{P}_{2}\right)$ e na segunda, as gerações segregantes $\mathrm{F}_{2}, \mathrm{RC}_{1}\left(\mathrm{P}_{1} \mathrm{xF}_{1}\right)$ e $\mathrm{RC}_{2}\left(\mathrm{P}_{2} \mathrm{xF}_{1}\right)$.

Os parentais $\left(\mathrm{P}_{1}\right.$ e $\left.\mathrm{P}_{2}\right)$ e as gerações segregantes $\mathrm{F}_{1}\left(\mathrm{P}_{1} \mathrm{x} \mathrm{P}_{2}\right), \mathrm{F}_{2}, \mathrm{RC}_{1}\left(\mathrm{P}_{1} \mathrm{XF}_{1}\right)$ e $\mathrm{RC}_{2}\left(\mathrm{P}_{2} \mathrm{XF}_{1}\right)$ foram avaliados em um experimento conduzido em campo, na Embrapa Meio-Norte, no ano de 2004. Nesse experimento, adotou-se o delineamento de blocos ao acaso com quatro repetições, sendo cada bloco constituído por 17 fileiras de $5 \mathrm{~m}$. Para os parentais $\mathrm{F}_{1} \mathrm{e}$ $\mathrm{RC}_{\mathrm{s}}$, as parcelas foram compostas de uma fileira e, para $\mathrm{F}_{2}$, foram utilizadas quatro fileiras. $\mathrm{O}$ espaçamento entre fileiras foi de $0,8 \mathrm{~m}$ e, entre plantas nas fileiras, de $0,25 \mathrm{~m}$. O comprimento do pedúnculo foi mensurado em dez plantas competitivas de cada fileira, como média de três pedúnculos: um da parte superior, um da média e um da inferior do ramo principal. 
Os estudos genéticos foram baseados em médias e variâncias, obtidas a partir de dados tomados nas seis populações, de acordo com a metodologia apresentada por Mather \& Jinks (1984) e Cruz et al. (2004), utilizando-se o programa computacional GENES (Cruz, 2001).

Os parâmetros estimados foram: média (m), variância aditiva (a), variância de dominância (d), variância epistática do tipo aditiva $\mathrm{x}$ aditiva (aa), variância epistática do tipo aditiva $\mathrm{x}$ dominante $(\mathrm{ad})$ e variância epistática do tipo dominante $\mathrm{x}$ dominante (dd). As estimativas de parâmetros foram baseadas em médias de populações, a partir do modelo completo, e calculadas por meio do método de mínimos quadrados ponderados, segundo Cruz et al. (2004).

\section{Resultados e Discussão}

As médias e variâncias estimadas para o caráter comprimento do pedúnculo mostraram que o contraste entre os genótipos parentais foi significativo (Tabela 1). O parental TE96-282-22G apresentou comprimento de pedúnculo acima de $42 \mathrm{~cm}$, enquanto o parental TVx5058-09C apresentou o comprimento de aproximadamente $19 \mathrm{~cm}$, valores próximos aos obtidos por Lopes et al. (2001), Singh (2003) e Lal et al. (2007). Esse contraste demonstra haver divergência entre os parentais, o que contribuiu para uma boa precisão no estudo de herança do caráter.

As médias das gerações $F_{1}$ e $F_{2}$ foram similares e intermediárias às médias dos parentais (Tabela 1). Isso indica que o tipo de interação alélica predominante entre os genes que condicionam a variabilidade para o comprimento do pedúnculo, em feijão-caupi, é aditiva.

Nos testes de significância da hipótese de nulidade dos parâmetros, estimados a partir do modelo completo, observou-se significância em todos os parâmetros

Tabela 1. Número de plantas $(\mathrm{N})$, média $(\bar{x})$, variância $\left(\sigma^{2}\right)$ e variância da média $\left(\mathrm{V}_{(\overline{\mathrm{x}})}\right)$ para o comprimento do pedúnculo $(\mathrm{cm})$ em seis populações $\left(\mathrm{P}_{1}, \mathrm{P}_{2}, \mathrm{~F}_{1}, \mathrm{~F}_{2}, \mathrm{RC}_{1}\right.$ e $\left.\mathrm{RC}_{2}\right)$ de feijãocaupi.

\begin{tabular}{lrrrr}
\hline População & $\mathrm{N}$ & $\overline{\mathrm{x}}$ & \multicolumn{1}{c}{$\sigma^{2}$} & $\mathrm{~V}_{(\overline{\mathrm{x}})}$ \\
\hline $\mathrm{P}_{1}(\mathrm{TE96-282-22G)}$ & 63 & 42,59 & 30,72 & 0,49 \\
$\mathrm{P}_{2}(\mathrm{TVx} 5058-09 \mathrm{C})$ & 68 & 18,95 & 8,28 & 0,12 \\
$\mathrm{~F}_{1}$ & 37 & 43,67 & 30,19 & 0,81 \\
$\mathrm{~F}_{2}$ & 274 & 36,13 & 76,50 & 0,28 \\
$\mathrm{RC}_{1}\left(\mathrm{~F}_{1}\right.$ x TE 96-282-22G) & 32 & 45,88 & 34,45 & 1,07 \\
$\mathrm{RC}_{2}\left(\mathrm{~F}_{1}\right.$ x TVx5058-09C) & 72 & 30,82 & 77,72 & 1,08 \\
\hline
\end{tabular}

avaliados, destacando-se o elevado valor de $t$ para o efeito gênico aditivo (Tabela 2). O efeito da variância de dominância foi maior do que o da variância aditiva (Tabela 3). Os testes de significância da hipótese de nulidade dos parâmetros estimados a partir do modelo reduzido são apresentados na Tabela 4 . $O$ valor de $t$ foi mais expressivo que o apresentado no modelo completo

Tabela 2. Teste de significância da hipótese de nulidade dos parâmetros genéticos estimados a partir do modelo completo, com base nas médias do comprimento do pedúnculo $(\mathrm{cm})$ obtidas a partir de plantas em seis populações $\left(\mathrm{P}_{1}, \mathrm{P}_{2}, \mathrm{~F}_{1}, \mathrm{~F}_{2}\right.$, $\mathrm{RC}_{1}$ e $\mathrm{RC}_{2}$ ) de feijão-caupi.

\begin{tabular}{ccrrc}
\hline Parâmetro $^{(1)}$ & Estimativa & Variância & \multicolumn{1}{c}{$\mathrm{t}$} & Graus de liberdade \\
\hline $\mathrm{m}$ & 21,90 & 13,24 & $6,02^{* *}$ & 504 \\
$\mathrm{a}$ & 11,82 & 0,15 & $30,27^{* *}$ & 129 \\
$\mathrm{~d}$ & 35,14 & 97,68 & $3,55^{* *}$ & 540 \\
$\mathrm{aa}$ & 8,86 & 13,09 & $2,45^{* *}$ & 375 \\
$\mathrm{ad}$ & 6,48 & 9,23 & $2,13^{*}$ & 231 \\
$\mathrm{dd}$ & $-13,37$ & 42,84 & $-2,04^{*}$ & 540 \\
\hline
\end{tabular}

${ }^{(1)} \mathrm{m}$, média das linhagens homozigóticas derivadas de $\mathrm{F}_{2}$; a, medida do efeito gênico aditivo; d, medida dos desvios de dominância; aa, medida das interações gênicas aditivo $\mathrm{x}$ aditivo; ad, medida das interações gênicas aditivo $\mathrm{x}$ dominante; dd, medida das interações gênicas dominante $\mathrm{x}$ do-

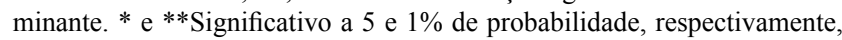
pelo teste $\mathrm{t}$.

Tabela 3. Análise de variância mostrando a decomposição não ortogonal da soma de quadrados de parâmetros (m, a, d, aa, ad, dd) pelo método de eliminação de Gauss, com base nas médias do comprimento do pedúnculo $(\mathrm{cm})$ obtidas a partir de plantas em seis populações $\left(\mathrm{P}_{1}, \mathrm{P}_{2}, \mathrm{~F}_{1}, \mathrm{~F}_{2}, \mathrm{RC}_{1} \mathrm{e}\right.$ $\mathrm{RC}_{2}$ ) de feijão-caupi.

\begin{tabular}{lcc}
\hline Fontes de variação & $(1)$ & $\mathrm{R}^{2}(\%)$ \\
\hline $\mathrm{m} / \mathrm{a}, \mathrm{d}, \mathrm{aa}, \mathrm{ad}, \mathrm{dd}$ & 36,23 & 3,70 \\
$\mathrm{a} / \mathrm{m}, \mathrm{d}, \mathrm{aa}, \mathrm{ad}, \mathrm{dd}$ & 916,64 & 93,51 \\
$\mathrm{~d} / \mathrm{m}, \mathrm{a}, \mathrm{aa}, \mathrm{ad}, \mathrm{dd}$ & 12,64 & 1,29 \\
$\mathrm{aa} / \mathrm{m}, \mathrm{a}, \mathrm{d}, \mathrm{ad}, \mathrm{dd}$ & 6,00 & 0,61 \\
$\mathrm{ad} / \mathrm{m}, \mathrm{a}, \mathrm{d}, \mathrm{aa}, \mathrm{dd}$ & 4,55 & 0,46 \\
$\mathrm{dd} / \mathrm{m}, \mathrm{a}, \mathrm{d}, \mathrm{aa}, \mathrm{ad}$ & 4,17 & 0,43 \\
\hline Total & 980,25 & 100 \\
\hline
\end{tabular}

${ }^{(1)} \mathrm{m}$, média das linhagens homozigóticas derivadas de $\mathrm{F}_{2}$; a, medida do efeito gênico aditivo; d, medida dos desvios de dominância; aa, medida das interações aditivo x aditivo; ad, medida das interações aditivo x dominante; $\mathrm{dd}$, medida das interações dominante $\mathrm{x}$ dominante.

Tabela 4. Teste de significância da hipótese de nulidade dos parâmetros genéticos estimados a partir do modelo aditivo-dominante, com base nas médias do comprimento do pedúnculo $(\mathrm{cm})$ obtidas a partir de plantas em seis populações $\left(\mathrm{P}_{1}, \mathrm{P}_{2}, \mathrm{~F}_{1}, \mathrm{~F}_{2}, \mathrm{RC}_{1}\right.$ e $\left.\mathrm{RC}_{2}\right)$ de feijão-caupi.

\begin{tabular}{cccc} 
Parâmetro $^{(1)}$ & Estimativa & Variância & $\mathrm{t}$ \\
\hline $\mathrm{m}$ & 30,83 & 0,13 & $83,69^{* *}$ \\
$\mathrm{a}$ & 11,99 & 0,14 & $32,28^{* *}$ \\
$\mathrm{~d}$ & 12,46 & 0,70 & $14,86^{* *}$ \\
\hline
\end{tabular}

${ }^{(1)} \mathrm{m}$, média das linhagens homozigóticas derivadas de $\mathrm{F}_{2}$; a, medida do efeito gênico aditivo; d, medida dos desvios de dominância. **Significativo a $1 \%$ de probabilidade. 
(Tabela 2). Para as variâncias, observaram-se valores muito baixos para todos os parâmetros, tendo o efeito de dominância maior valor. Isso provavelmente se deve ao fato de se ter eliminado o efeito da epistasia no modelo simplificado.

A decomposição não ortogonal da soma de quadrados dos parâmetros (m, a, d, aa, ad, dd) para o caráter comprimento de pedúnculo é apresentada na Tabela 5. Os valores de $\mathrm{R}^{2}$ indicam que os efeitos genéticos mais importantes foram os aditivos, seguidos pela média, e ressaltam a contribuição desses efeitos para a variação observada para o comprimento do pedúnculo, ao contrário dos efeitos de dominância, que contribuíram menos para a variação total. A existência de variância aditiva é um indicativo da facilidade de identificação de genótipos superiores (Cruz et al., 2004). Os métodos de melhoramento que se beneficiam da alta variância aditiva para a obtenção de ganhos genéticos são mais importantes no melhoramento de espécies autógamas (Gravina et al., 2004). Como os efeitos aditivos foram significativos, os ganhos preditos com a seleção para o comprimento do pedúnculo em feijão-caupi poderão ser alcançados.

As interações epistáticas também apresentaram valores muito baixos, sendo o componente aditivo $\mathrm{x}$ aditivo (aa) o mais importante (Tabela 5). Isso indica que os efeitos de interação explicam muito pouco da variância observada no modelo completo, e que os efeitos da média, principalmente o efeito aditivo, são mais importantes para o modelo. Esse resultado discorda parcialmente do encontrado por Pal et al. (2003), que afirmaram que o comprimento do pedúnculo está sob ação gênica não aditiva.

Para avaliar a adequação do modelo aditivodominante, correlacionaram-se os valores entre

Tabela 5. Análise de variância mostrando a decomposição não ortogonal da soma de quadrados de parâmetros $(\mathrm{m}, \mathrm{a}, \mathrm{d})$ pelo método de eliminação de Gauss, com base nas médias do comprimento do pedúnculo $(\mathrm{cm})$ em seis populações $\left(\mathrm{P}_{1}\right.$, $\mathrm{P}_{2}, \mathrm{~F}_{1}, \mathrm{~F}_{2}, \mathrm{RC}_{1}$ e $\mathrm{RC}_{2}$ ) de feijão-caupi.

\begin{tabular}{lcr}
\hline Fonte de variação & \\
\hline $\mathrm{m} / \mathrm{a}, \mathrm{d}$ & Soma de quadrados & \multicolumn{1}{c}{$\mathrm{R}^{2}$} \\
$\mathrm{a} / \mathrm{m}, \mathrm{d}$ & $7.004,81$ & 84,72 \\
$\mathrm{~d} / \mathrm{m}, \mathrm{a}$ & $1.042,04$ & 12,60 \\
Total & 220,94 & 2,67 \\
\hline
\end{tabular}

${ }^{(1)} \mathrm{m}$, média das linhagens homozigóticas derivadas de $\mathrm{F}_{2} ; \mathrm{a}$, medida do efeito gênico aditivo; d, medida dos desvios de dominância. as médias observadas e estimadas (Tabela 6). O coeficiente de correlação próximo da unidade indica uma alta precisão do modelo para o caráter comprimento do pedúnculo.

A decomposição não ortogonal para o modelo reduzido $(\mathrm{m}, \mathrm{a}, \mathrm{d})$ mostra que o modelo genético aditivo-dominante foi satisfatório para explicar a variabilidade aditiva presente em $F_{2}$, pois a expressão do efeito aditivo foi superior à dominância (Tabela 7). Observa-se que houve predominância da variação genotípica sobre a ambiental. A variância aditiva foi o componente mais importante da variância genética para o caráter, enquanto a variância de dominância foi a menor de todas. Efeito genético aditivo também foi observado por Lopes et al. (2003) para o caráter tamanho do grão em feijão-caupi. Ramalho et al. (1993) consideram a variância aditiva como a mais importante para o melhorista e é ela a responsável pelo efeito positivo da seleção.

Tabela 6. Média observada (Y-observado) e estimada (Y-estimado) para o comprimento do pedúnculo $(\mathrm{cm})$, obtidas a partir de plantas em seis populações $\left(\mathrm{P}_{1}, \mathrm{P}_{2}, \mathrm{~F}_{1}, \mathrm{~F}_{2}\right.$, $\mathrm{RC}_{1}$ e $\mathrm{RC}_{2}$ ) de feijão-caupi.

\begin{tabular}{lcc}
\hline Populações & Y-observado & Y-estimado \\
\hline $\mathrm{P}_{1}$ (TE96-282-22G) & 42,59 & 42,82 \\
$\mathrm{P}_{2}$ (TVX5058-09C) & 18,95 & 18,84 \\
$\mathrm{~F}_{1}$ & 43,67 & 43,29 \\
$\mathrm{~F}_{2}$ & 36,13 & 37,06 \\
$\mathrm{RC}_{1}\left(\mathrm{~F}_{1}\right.$ x TE 96-282-22G) & 45,88 & 43,06 \\
$\mathrm{RC}_{2}\left(\mathrm{~F}_{1}\right.$ x TVX5058-09C) & 30,82 & 31,07 \\
\hline $\mathrm{R}(\mathrm{Y}$-observado, Y-estimado) & 0,99 & \\
\hline $\mathrm{R}^{2}(\%)$ & 98 & \\
\hline
\end{tabular}

Tabela 7. Estimativas das variâncias fenotípica, genotípica, aditiva, de dominância e de ambiente, das herdabilidades no sentido amplo e restrito, do grau médio de dominância e do número de genes que controlam o caráter comprimento do pedúnculo, obtidas a partir de plantas em seis populações $\left(\mathrm{P}_{1}, \mathrm{P}_{2}, \mathrm{~F}_{1}, \mathrm{~F}_{2}, \mathrm{RC}_{1}\right.$ e $\left.\mathrm{RC}_{2}\right)$ de feijão-caupi.

\begin{tabular}{lc}
\hline Parâmetro & Estimativa \\
\hline Variância fenotípica & 76,50 \\
Variância genotípica & 51,66 \\
Variância de ambiente & 24,84 \\
Variância aditiva & 40,83 \\
Variância de dominância & 10,83 \\
Herdabilidade no sentido amplo (\%) & 67,52 \\
Herdabilidade no sentido restrito (\%) & 53,37 \\
Grau médio de dominância & 0,72 \\
Número de genes que controlam o caráter & 5 \\
\hline
\end{tabular}


Os coeficientes de herdabilidades no sentido amplo e restrito mostraram magnitudes de intermediária a alta (Tabela 7), demonstrando que a maior parte do fenótipo é atribuída a causas genéticas. Segundo Rocha et al. (2003), herdabilidades desta magnitude indicam que há amplas possibilidades de ganhos genéticos para o caráter com a seleção. A magnitude encontrada para o grau médio de dominância (Tabela 7) revela a existência de dominância parcial no controle do comprimento do pedúnculo. $\mathrm{O}$ valor positivo para a estimativa indica que a dominância ocorre em direção à manifestação fenotípica de maior grandeza do caráter, ou seja, pedúnculos longos foram parcialmente dominantes sobre pedúnculos curtos.

$\mathrm{O}$ número de genes que controlam o comprimento do pedúnculo em feijão-caupi foi igual a cinco (Tabela 7). Resultado semelhante foi obtido por Lopes et al. (2003) para o caráter tamanho do grão. Essa estimativa é útil como indicador da natureza poligênica e probabilidade de se obter genótipos favoráveis para o comprimento do pedúnculo em feijão-caupi. Poucos genes, baixa influência do ambiente e alta proporção da variância aditiva na expressão da variância genética implicam maior facilidade no melhoramento com vistas à obtenção de genótipos com pedúnculos curtos.

\section{Conclusões}

1. Oefeito gênico mais importante na determinação do comprimento do pedúnculo é o de natureza aditiva, com controle genético oligogênico.

2. A herança relativamente simples, associada a uma herdabilidade alta, favorece a prática da seleção e ganhos satisfatórios para o melhoramento do comprimento do pedúnculo em feijão-caupi.

\section{Agradecimentos}

Aos funcionários Agripino Ferreira do Nascimento, Ivo de Sousa Pinto, Manoel Gonçalves da Silva e Paulo Sérgio Monteiro, da Embrapa MeioNorte, pelo apoio na condução do experimento.

\section{Referências}

ARIYO, O.J. Genetic variability, correlations and path analysis of components of seed yield in cowpea (Vigna unguiculata). Pertanika Journal of Tropical Agricultural Science, v.18, p.63-69, 1995.
CRUZ, C.D. Programas Genes: versão Windows: aplicativo computacional em genética e estatística. Viçosa: UFV, 2001. $648 \mathrm{p}$.

CRUZ, C.D.; REGAZZI, A.J.; CARNEIRO, P.C.S. Modelos biométricos aplicados ao melhoramento genético. 3.ed. Viçosa: UFV, 2004. 480p.

FREIRE FILHO, F.R.; LIMA, J.A. de A.; RIBEIRO, V.Q. (Ed.). Feijão-caupi: avanços tecnológicos. Brasília: Embrapa Informação Tecnológica, 2005. 519p.

FREIRE FILHO, F.R.; ROCHA, M. de M.; RIBEIRO, V.Q.; SITOLLIN, I.M. Avanços e perspectivas para a cultura do feijão-caupi. In: ALBUQUERQUE, A.C.S.; SILVA, A.G. da (Ed.). Agricultura tropical: quatro décadas de inovações tecnológicas, institucionais e políticas. Brasília: Embrapa Informação Tecnológica, 2008. v.1, p.285-250.

FROTA, A.B.; FREIRE FILHO, F.R.; CÔRREA, M.P.F. Impactos socioeconômicos das cultivares de feijão-caupi na região Meio-Norte do Brasil. Teresina: Embrapa Meio-Norte, 2000. 26p. (Embrapa Meio-Norte. Documentos, 52).

GITHIRI, S.M.; KIMANI, P.M.; PATHAK, R.S. Linkage relationships among loci controlling morphological traits in cowpea [Vigna unguiculata (L.) Walp.]. Euphytica, v.92, p.307-331, 1996.

GRAVINA, G. de A.; MARTINS FILHO, S.; SEDIYAMA, C.S.; CRUZ, C.D. Parâmetros genéticos da resistência da soja a Cercospora sojina. Pesquisa Agropecuária Brasileira, v.39, p.653-659, 2004.

KEHINDE, O.B.; MYERS, G.O.; FAWOLE, I. Analysis of genetic linkage in the cowpea Vigna unguiculata (L.) Walp. Pertanika Journal of Tropical Agricultural Science, v.20, p.75-82, 1997.

LAL, H.; RAI, M.; KARAN, S.; VERMA, A.; RAM, D. Multivariate hierarchical clustering of cowpea germplasm [Vigna unguiculata (L.) Walp.]. Acta Horticulturae, v.752, p.413-416, 2007.

LOPES, A.C. de A.; FREIRE FILHO, F.R.; SILVA, R.B.Q. da; CAMPOS, F.L.; ROCHA, M. de M. Variabilidade entre caracteres agronômicos em caupi (Vigna unguiculata). Pesquisa Agropecuária Brasileira, v.36, p.515-520, 2001.

LOPES, F.C. da C.; GOMES, R.L.F.; FREIRE FILHO, F.R. Genetic control of cowpea seed sizes. Scientia Agricola, v.60, p.315-318, 2003.

MACHADO, C. de F.; FREIRE FILHO, F.R.; RIBEIRO, V.Q.; COSTA, D.S.S.; AMORIM, A.F. de. Herança da inflorescência composta da cultivar de feijão-caupi Cacheado. Ciência e Agrotecnologia, v.31, p.1347-1350, 2007.

MATHER, K.; JINKS, J.L. Introdução à genética biométrica. Ribeirão Preto: Sociedade Brasileira de Genética, 1984. 242 p.

MATOS FILHO, C.H.A. Análise genética de caracteres relacionados à arquitetura de planta em feijão-caupi. 2004. 57p. Dissertação (Mestrado) - Universidade Federal do Piauí, Teresina. 
PAL, A.K.; SINGH, B.; MAURYA, A.N. Inbreeding depression in cowpea (Vigna unguiculata (L.) Walp.). Journal of Applied Horticulture, v.5, p.105-107, 2003.

RAMALHO, M.A.P.; SANTOS. J.B. dos; ZIMMERMANN, M.J.O. Genética quantitativa em plantas autógamas: aplicações ao melhoramento do feijoeiro. Goiânia: UFG, 1993. 171p.

ROCHA, M.M.; CAMPELO, J.E.G.; FREIRE FILHO, F.R.; RIBEIRO, V.Q.; LOPES, A.C.A. Estimativas de parâmetros genéticos em genótipos de feijão-caupi de tegumento branco. Revista Científica Rural, v.8, p.135-141, 2003.

SINGH, B.B.; AJEIGBE, H.A.; TARAWALI, S.A.; FERNANDEZRIVERA, S.; ABUBAKAR, M. Improving the production and utilization of cowpea as food and fodder. Field Crops Research, v.84, p.169-177, 2003.

SINGH, B.B.; ISHIYAKU, M.F. Genetics of rough seed coat texture in cowpea. Journal of Heredity, v.91, p.170-174, 2000.

Recebido em 21 de outubro de 2008 e aprovado em 27 de fevereiro de 2009 